SISTEMA
ELETRÔNICO
DE REVISTAS
SER I UfPR

\title{
A rede sociotécnica na relação entre ribeirinhos e onças (Panthera onca e Puma concolor) nas Reservas de Desenvolvimento Sustentável Amanã e Mamirauá no Amazonas
}

\section{The Socio-Technical Relationship between Riverside Inhabitants and Big Cats (Panthera onca and Puma concolor) in the Sustainable Development Reserves of Amanã and Mamirauá in the Amazon}

\author{
Joana Silva MACEDO ${ }^{1,2^{*}}$, Fátima Tereza Braga BRANQUINHO ${ }^{3}$, Helena de Godoy BERGALLO ${ }^{4}$ \\ ${ }^{1}$ Instituto de Desenvolvimento Sustentável Mamirauá, Tefé, AM, Brasil. \\ ${ }^{2}$ Programa de Pós-Graduação em Meio Ambiente, Universidade Estadual do Rio de Janeiro (UERJ), Rio de Janeiro, RJ, Brasil. \\ ${ }^{3}$ Departamento de Ciências Sociais e Educação, Universidade do Estado do Rio de Janeiro (UERJ), Rio de Janeiro, RJ, Brasil. \\ ${ }^{4}$ Departamento de Ecologia, Universidade do Estado do Rio de Janeiro (UERJ), Rio de Janeiro, RJ, Brasil. \\ ${ }^{*}$ E-mail de contato: joanasm@terra.com.br
}

Artigo recebido em 26 de março de 2015, versão final aceita em 17 de novembro de 2015.

RESUMO: Estudos conduzidos por cientistas naturais sobre a relação entre fauna silvestre e populações tradicionais muitas vezes não apontam a assimetria e as controvérsias inerentes ao tema, principalmente quando tratam da fauna carismática. $\mathrm{O}$ embate entre modos tradicionais de lidar com os problemas advindos da convivência com onças e o empenho em conservar esses animais está se dando em uma arena onde o diálogo é falho. O objetivo do artigo foi apresentar a rede sociotécnica desse conflito. Ao assumir a Teoria Ator-Rede como método para analisar essa relação, espera-se dar um passo para a composição de um mundo comum que considere de forma simétrica os humanos e não-humanos que compõem a rede. Os atores, suas práticas e conexões na rede e as dissonâncias nos discursos foram apresentados procurando seguir alguns preceitos básicos da teoria, como adotar a política como parte do fazer científico, abandonar a divisão modernista e as representações e assumir a multiplicidade ontológica.

Palavras-chave: Teoria Ator-Rede; rede sociotécnica; onças; ribeirinhos; Amazônia.

ABSTRACT: Studies conducted by natural scientists on the relationship between wildlife and traditional populations often do not indicate the inherent asymmetry and controversies of the subject, especially when dealing with charismatic fauna. The clash between traditional ways of dealing with the problems arising from the coexistence with big cats and the commitment to preserve these animals is taking place in an arena with little room for dialog. The 
objective of this paper was to present the socio-technical relationship of this conflict. By taking the Actor-Network Theory as a method to analyze this relationship, we hope to take a step towards the composition of a common world that considers the humans and non-humans that make up the network in a symmetric way. The actors, their practices and connections in the network, and the dissonances in discourses were presented according to some basic rules of the theory, such as adopting policy as part of the scientific process, abandoning the modernist division and representations, and accepting the ontological multiplicity.

Keywords: Actor-Network Theory; socio-technical network; jaguar; riverside dwellers; Amazon.

\section{Introdução}

\subsection{Homens e outros predadores}

A relação entre carnívoros de grande porte, tais como ursos, lobos e grandes felinos, e populações humanas foi desde sempre complexa e controversa. Ao mesmo tempo em que esses animais geram fascínio e fazem parte da mitologia e do imaginário dos povos que com eles convivem (até mesmo das populações urbanas contemporâneas), os custos infringidos pela relação direta por vezes são altos (Kruuk, 2002). A predação de animais domésticos e o medo de um ataque, baseado em fatos concretos ou não, marcam os impactos negativos causados por esses animais.

Os impactos negativos embutidos nessa relação, que remonta aos primórdios da domesticação de animais para "estocar" proteína, foi, tradicionalmente, tratado com o controle da abundância de predadores por abates (Treves et al., 2006). Algumas culturas desenvolveram maiores níveis de tolerância a esses animais, pautadas em reverências, crenças e mitos e na aceitação de suas agências enquanto carnívoros (Quammen, 2007; Krithivasan et al., 2009). Outras, pautadas em uma lógica utilitarista e em um desejo de "domar" a natureza, trataram grandes carnívoros como pragas e empreenderam esforços para exterminá-los, obtendo êxito algumas vezes, como no emblemático caso do tilacino ${ }^{1}$ (McKnight, 2008).
A partir do fortalecimento e da disseminação do debate ambientalista, a proteção desses animais passa a ser reivindicada (Linnell, 2013). Esse é um movimento relativamente recente, teve início há cerca de 50 anos, e provocou mudanças nas leis, criações de Unidades de Conservação (UCs), reintroduções bem-sucedidas em alguns pontos onde houve extinções locais e a mobilização da opinião pública, sobretudo urbana, em favor dos carnívoros.

No entanto, os impactos negativos decorrentes da convivência com esses animais continuam e populações humanas, em resposta aos prejuízos e à insegurança, prosseguem com os abates. Para contornar essa situação e proteger os grandes predadores, alguns deles seriamente ameaçados de extinção, cientistas e conservacionistas começaram a pesquisar formas de diminuir o número de abates por retaliação ou prevenção de danos, envolvendo as populações humanas que dividem território com carnívoros e seus modos de manejar as criações domésticas (Sillero-Zubiri et al., 2006). Agora, além da relação de competição entre humanos e predadores silvestres, há também uma disputa entre humanos com distintas visões sobre o tema: de um lado, a preocupação com a segurança, a subsistência e as perdas econômicas e, do outro, a preocupação com a extinção de espécies e o equilíbrio ambiental (Redpath et al., 2015). A esse ramo de estudo dá-se o nome de Conflitos ${ }^{2}$ entre Homens e a Fauna Silvestre (Human-wildlife conflicts).

Os conflitos não envolvem apenas grandes predadores, outras espécies carismáticas ${ }^{3}$ também geram danos

\footnotetext{
${ }^{1}$ A extinção dos tilacinos, conhecidos popularmente como tigre-da-Tasmânia ou lobo-da-Tasmânia, foi atribuída aos esforços empreendidos para exterminar esses animais para proteção de rebanhos de ovelhas. O governo da Tasmânia pagava recompensas por tilacino abatido.

${ }^{2}$ Há controvérsias sobre a pertinência da palavra conflito para designar essa relação negativa com a fauna silvestre e seus desdobramentos, mas o termo já se consolidou na literatura internacional sobre o tema e por isso será adotado aqui.

${ }^{3}$ Fauna carismática é um termo usado para espécies animais que, seja por sua beleza, porte ou carisma atribuído, exercem grande apelo popular para a causa conservacionista. Panda gigante, baleias e tigres são proeminentes exemplos de animais que atraem atenção do público por qualidades estéticas e/ou imponência.
} 
e temores para uns e provocam fascínio e compaixão em outros, como, por exemplo, os elefantes. É um tema complexo, uma vez que abarca a proteção a espécies ameaçadas, o manejo de animais domésticos, as relações subjetivas entre pessoas e animais e a negociação entre atores humanos com claro conflito de interesses. Para a gestão do conflito, se faz necessária uma abordagem interdisciplinar, que concilie as necessidades das populações humanas afetadas com a manutenção dos animais silvestres envolvidos (Treves et al., 2006; Linnell, 2013).

Muitos estudos foram feitos recomendando ferramentas e métodos para a gestão do conflito com a fauna (Treves \& Karanth, 2003; Madden, 2004; Treves et al., 2006; Dickman, 2010). Todos eles indicam que o ponto essencial para a mitigação de conflitos é o envolvimento das populações afetadas nas buscas por soluções. No Brasil, no entanto, a relação conflituosa entre populações humanas e a fauna silvestre é na maior parte das vezes trabalhada por profissionais das ciências naturais com pouca ou nenhuma familiaridade com métodos e ferramentas para mediar o conflito entre atores humanos ou entender as motivações e anseios das populações afetadas. Poucos estudos sobre o tema consideraram a dimensão humana do problema (Amâncio et al., 2007; Marchini, 2010). As discussões para a mitigação acabam esbarrando em legislações rígidas e discursos ambientalistas que, muitas vezes, não consideram a diversidade de situações e a vulnerabilidade das populações afetadas.

\subsection{A Teoria Ator-Rede e a relação entre onças e ribeirinhos na Amazônia}

A Teoria Ator-Rede, desenvolvida por Bruno Latour (1994), tem como base a noção de rede, que remete a relações e ações entre atores humanos e não-humanos. Relações essas que não são fixas e não podem ser previstas, que têm forma de alianças fluidas e mediações. Não havendo modelo teórico para descrever ou prever o comportamento da rede, é preciso seguir os atores, investigar suas agências e conexões. Essa ideia de rede, de natureza heterogênea e dinâmica, é aplicada como método para analisar como se dá a construção do conhecimento, no ramo de estudos denominado antropologia das ciências e das técnicas (Latour, 1993; 1999; 2001; Callon et al., 2001). A principal pergunta que norteou o trabalho de antropólogos e sociólogos das ciências e das técnicas, em suas diferentes formulações, pode ser expressa do seguinte modo: como o objeto, que não tem a mesma natureza da sociedade, é produzido por essa sociedade e tal como ela tem a capacidade de recompor laços sociais (Blandin, 2002)?

A grosso modo, é como aplicar o método etnográfico, voltando sua lente não para descrever "os outros"4 $\mathrm{e}$ sim aos próprios cientistas, suas técnicas, instrumentos, produtos e tudo o mais que envolve a construção do conhecimento, no que Latour chamou de rede sociotécnica. O foco central desses estudos são as interações, mediações entre atores capazes de produzir mudanças, uma vez que afetam e influenciam mutuamente os elementos que compõem a rede. Ou seja, os componentes da rede, sejam humanos ou não-humanos, não determinam uns aos outros via interações, mas exercem influência uns sobre os outros. Isso pressupõe abandonar a ideia de sujeito e objeto, assim como a separação entre natureza e cultura e entre política e ciência.

Outro ponto importante, ao assumir a Teoria Ator-Rede como referencial teórico-metodológico, é incorporar o princípio da simetria, que postula que, uma vez que os atores possuem iguais possibilidades de produzir interferência e mediação, seus discursos e agências não podem ser hierarquizados. Ao adotar o princípio da simetria, os discursos dissonantes são acolhidos com igual peso e as controvérsias são assumidas de forma a permitir a existência de ontologias múltiplas.

Estudos conduzidos no Brasil por cientistas naturais sobre a relação entre fauna silvestre e populações tradicionais em geral não apontam a assimetria e as controvérsias inerentes ao tema. Ao assumir a Teoria Ator-Rede como método para analisar essa relação, espera-se

\footnotetext{
${ }^{4}$ Tradicionalmente o foco dos etnógrafos são povos "primitivos" ou minorias excluídas que eles não reconhecem como "iguais", sendo em contrapartida denominados como "outros". Como pontuou Viveiros de Castro (2010), "Antropologia é o estudo do homem, mas, ao mesmo tempo, do homem mais diferente possível daquele que enuncia o discurso da Antropologia: o selvagem, o primitivo".
} 
superar essa dificuldade. Sá (2013) e Süssekind (2014), tendo como foco o muriqui (Brachyteles hipoxanthus) de Caratinga e a onça-pintada (Panthera onca) pantaneira, respectivamente, usaram essa ferramenta metodológica para análise das relações entre não-humanos, cientistas, moradores locais, ambientalistas e suas agências.

O presente artigo tem como objetivo abordar a relação entre onças ( $P$. onca e Puma concolor) e populações ribeirinhas, bem como seus desdobramentos, através da rede sociotécnica dessa relação, descrevendo seus atores e agências. Considero que a relevância da adoção da Teoria Ator-Rede para tratar do conflito existente nessa relação resida principalmente no fato de que esse tema tem sido tratado de forma acentuadamente assimétrica.

Consolidar a visão de que as questões ambientais são em última instância problemas que envolvem humanos e, portanto, precisam ampliar suas ferramentas para além do escopo das ciências naturais é a contribuição mais ampla almejada por esse artigo. E, mais especificamente ajudar a diminuir o atrito na relação entre povos da floresta, onças e cientistas/conservacionistas, contemplando os anseios dos ribeirinhos e a conservação dos felinos. Compor a rede da relação ribeirinho-onças inclui identificar os atores, coletar suas vozes e expor essas vozes a uma consulta que considere a pertinência e a adequação ao mundo comum $^{5}$ das proposições que emergem dessa relação.

$\mathrm{O}$ artigo trata especificamente da relação entre onças e populações tradicionais ${ }^{6}$ nas Reservas de Desenvolvimento Sustentável (RDS) Mamirauá e Amanã, na região do Médio Solimões, Estado do Amazonas (Figura 1). O estudo foi feito com base em entrevistas semiestruturadas, reuniões e conversas informais com os ribeirinhos das duas Reservas entre 2010 e 2013, na experiência de trabalhar com ecologia de onças entre 2007 e 2011, nas interações com pesquisadores, gestores e ambientalistas e em pesquisas bibliográficas sobre outros atores que compõem essa rede.

\section{A rede da relação ribeirinho-onça: atores $e$ agências}

Partindo do conceito de rede sociotécnica, foi feito um esboço da rede que envolve a relação entre onças e ribeirinhos. Essa rede, composta de atores humanos e não-humanos, conecta, além de ribeirinhos e onças, os animais domésticos, os modos de produção, a floresta e seu mosaico de áreas de uso, a caça, as armas, os representantes de órgãos ambientais, os gestores das Reservas, pesquisadores, ambientalistas, a legislação, a opinião pública, entre outros grupos em formação no espaço de tempo da pesquisa. Pode-se identificar atores locais, como os ribeirinhos e as onças, e contextos globais, como a opinião pública e as listas vermelhas de animais ameaçados. Para construir a rede, no entanto, é preciso seguir continuamente a conexão entre atores locais e contextos gerais, de modo que se possa visualizá-los num mesmo plano sem distinções entre local e global (Latour, 2012).

\subsection{Os ribeirinhos}

Ribeirinho ou caboclo é um termo usado para definir uma população rural da Amazônia que foi formada principalmente por imigrantes nordestinos e índios. Como referência para descrever a população ribeirinha no Amazonas foi usada como fonte a tese de Débora Lima (Lima-Ayres, 1992), que chama de caboclo o ribeirinho amazonense e remonta à história da formação desse povo desde a ocupação colonial por imigrantes portugueses, a dinâmica das etnias indígenas, as missões católicas e os imigrantes nordestinos dos dois ciclos da borracha. Desses eventos e dessa mistura resultou a sociedade rural que hoje habita as margens de rios e lagos na Amazônia. Muitos vivem em comunidades, que são conjuntos de casas, onde as famílias residentes têm normalmente

\footnotetext{
${ }^{5}$ Latour (1999) define como mundo comum "o resultado provisório da unificação progressiva das realidades exteriores". Compor o mundo comum é caminhar na direção de admitir que o mundo é mais do que plural ou diverso, é comum a todos seus habitantes, sejam eles humanos ou não-humanos.

${ }^{6} \mathrm{O}$ termo populações tradicionais refere-se aqui a grupos humanos que compartilham dimensões históricas, culturais e políticas particulares, como, por exemplo, ribeirinhos amazônicos, quilombolas e caiçaras. A identidade cultural e o modo de se relacionar e obter recursos da natureza são reconhecidos, sem, no entanto, negar o dinâmico processo de mudanças culturais e conectividade com outros grupos. Para mais detalhes sobre a definição de populações tradicionais adotada, ver Castro e colaboradores (2006) e Lima-Ayres (1992).
} 


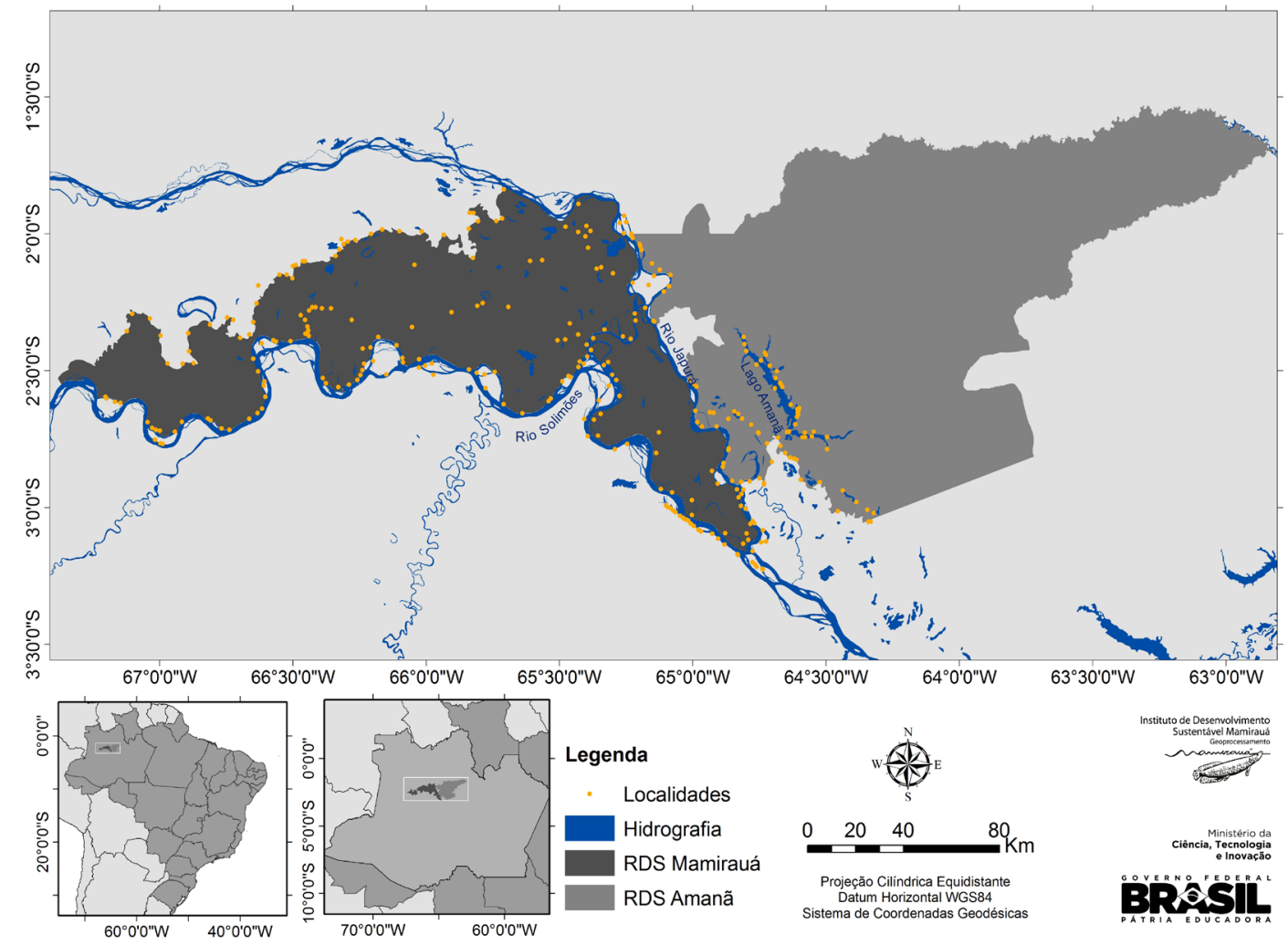

FIGURA 1 - Mapa com os limites das Reservas de Desenvolvimento Sustentável Mamirauá (cinza escuro) e Amanã (cinza claro) e sua localização no Estado do Amazonas. Os assentamentos humanos (comunidades e sítios) estão representados pelos pontos amarelos.

laços de parentesco (Lima-Ayres \& Alencar, 2000). As RDS Mamirauá e Amanã, de acordo com o último censo feito em 2011 (Moura et al., 2015), abrigam 13.084 moradores distribuídos em 207 localidades, constituídas por comunidades e sítios.

A concepção da pesquisa que precede esse artigo foi feita com base nas constantes queixas e nos relatos sobre a convivência com as onças por parte dos ribeirinhos. Esses relatos revelaram um desejo de que eles, enquanto habitantes de uma Unidade de Conservação e cientes das implicações disto, também fossem levados em consideração no que tange à pesquisa e à gestão da fauna. Ao ouvir diversas vezes a pergunta "Pode uma onça valer mais que um cristão?" (comunicação pessoal) e algumas variações da mesma, é possível visualizar não só os problemas provenientes da convivência direta com esses animais, mas principalmente o ressentimento em relação à atenção dada por pesquisadores/gestores/ opinião pública à conservação em detrimento de suas necessidades. Essa frase, bem como suas variações, é usada para externar a perplexidade com o fato que o abate de onças, no entendimento deles, é proibido mesmo quando eles percebem uma ameaça, real ou potencial, às suas próprias vidas ${ }^{8}$. Os riscos da convivência com as

${ }^{7}$ Todas as citações e relatos são anônimos. Isso foi acordado no momento das entrevistas, reuniões e conversas com ribeirinhos por causa das recorrentes referências a abates ilegais de onças.

${ }^{8}$ Muitos ribeirinhos e mesmo analistas ambientais desconhecem que não é crime abater um animal silvestre em caso de ataque. 
onças, mesmo que sejam por vezes superdimensionados pelos ribeirinhos, devem ser levados em consideração pelos técnicos. É sabido que relações conflituosas com a fauna podem se intensificar quando as populações locais afetadas entendem que é dada prioridade para a conservação em detrimento de suas necessidades e valores e quando elas não são adequadamente envolvidas na busca de soluções para os problemas de convivência com animais silvestres (Madden, 2004; Treves et al., 2006; Linnell, 2015).

Os ribeirinhos moradores das RDS Mamirauá e Amanã criam animais domésticos para subsistência e complementação de renda. Perdas de animais podem representar prejuízo econômico e comprometer a segurança alimentar da família. Além disso, quando as onças rondam as residências em busca de animais, eles temem pela segurança da família, especialmente das crianças. Apesar dos relatos expressarem muitas vezes respeito e admiração pelas onças, eles lidam com um problema concreto que acabam resolvendo por conta própria com abates. Os ribeirinhos clamam por solução para esses problemas, mas suas vozes não alcançam as esferas políticas. Alegam que não podem arcar sozinhos com os custos da conservação. Muitos deles defendem que deveria haver um manejo de onças, uma forma de controlar o número desses animais de forma legal. Afirmam que há onças demais no lugar onde vivem.

Ribeirinhos agem e reagem às onças. Movidos por vingança, medo, raiva, prevenção ou mesmo para subjugar a "fera", abatem onças com frequência. Nas RDS Mamirauá e Amanã, uma estimativa de abates anuais chegou ao número de 44,5 onças-pintadas e 9,7 onças-vermelhas mortas anualmente (Valsecchi, 2012). A maior parte dos abates relatados em entrevistas $(51,2 \%$ de um total de 123 abates) teve como motivo declarado a retaliação pela predação (realizada ou potencial) de animais domésticos. Também foram declarados como motivo para o abate o medo/defesa de um ataque $(23,5 \%)$, abates sem motivo declarado (16,2\%), a defesa de cães de caça $(4,8 \%)$, a caça para o consumo da carne $(3,2 \%)$ e o abate para a captura de filhotes $(0,8 \%)$ (Macedo, 2015). A falta de motivo dá a entender que o abate foi recreativo ou motivado por uma demonstração de força, em que o caçador se satisfaz subjugando um animal que ele reconhece como forte ou potencialmente perigoso.
Ribeirinhos agem também ao relatar histórias de onças, que incluem acidentes, sustos e caçadas. Umas são frutos de experiência própria, outras relatos antigos e por vezes fantásticos do "tempo do couro", quando matar onça-pintada rendia dinheiro. Outras são piadas e brincadeiras, como contam os "valentes" que, ao encontrar uma onça, amarram-na, dão uma surra de cinto e depois aconselham, para que não se aproxime mais. $\mathrm{O}$ fato é que histórias sobre onças são recorrentes em rodas de conversas. Narram coragem épica, covardia extrema, caçadas com zagaia, ataques frustrados, sustos e outros causos.

O relato do ribeirinho é uma importante trilha a ser seguida. Esses relatos ora guiam pelas florestas os caminhos e encontros com as onças, com fascinantes detalhes sobre seu comportamento, ora vão até a opinião pública, que aparece via interações com pesquisadores, extensionistas, turistas e programas de TV. Os relatos também levam ao IBAMA, às leis de proteção à fauna e aos gestores das Unidades de Conservação e todos os desdobramentos que a legislação, o plano de gestão da UC e os seus atores representam em relação à convivência com as onças.

\subsection{As onças}

A onça-pintada e a onça-parda são os maiores felinos das Américas e também os que mais geram relações conflituosas (Inskip \& Zimmermann, 2009). A conversão de habitat é a principal ameaça enfrentada por esses animais, seguida pelos abates em retaliação à predação de animais domésticos (Sanderson et al., 2002). Ocorrem em densidades naturalmente baixas e precisam de uma área de vida que pode chegar a mais de $200 \mathrm{~km}^{2}$ (Silveira, 2004).

As onças são classificadas como espécie chave, carismática, bandeira e guarda-chuva, o que significa que têm importância para a manutenção do equilíbrio dos ecossistemas, forte apelo para a causa conservacionista, conseguem mobilizar a opinião pública e atrair investimentos em conservação e sua proteção tem como consequência a proteção do habitat que ocupam e beneficiam várias outras espécies. São ainda classificadas, quanto ao risco de extinção, de acordo com critérios preestabelecidos por especialistas (IUCN, 2012), nas categorias apresentadas na tabela a seguir (Tabela 1). 
TABELA 1 - Status de conservação da onça-pintada (Panthera onca) e onça-vermelha (Puma concolor) de acordo com a Lista Vermelha internacional da International Union for Conservation of Nature (IUCN), e as Listas Vermelhas do Brasil e dos Estados do Rio Grande do Sul, Santa Catarina, Paraná, Minas Gerais, São Paulo, Rio de Janeiro, Espírito Santo e Pará. Categorias de ameaça: CR - criticamente ameaçada; EN - ameaçada; VU vulnerável; NT - quase ameaçada; LC - baixo risco.

\begin{tabular}{lcc}
\hline \multicolumn{1}{c}{ Lista } & $\begin{array}{c}\text { Onça- } \\
\text { pintada }\end{array}$ & $\begin{array}{c}\text { Onça- } \\
\text { vermelha }\end{array}$ \\
\hline IUCN & $\mathrm{NT}$ & $\mathrm{LC}$ \\
Lista vermelha - Brasil & $\mathrm{VU}$ & $\mathrm{VU}$ \\
Lista vermelha - Rio Grande do Sul & $\mathrm{CR}$ & $\mathrm{EN}$ \\
Lista vermelha - Santa Catarina & $\mathrm{CR}$ & $\mathrm{VU}$ \\
Lista vermelha - Paraná & $\mathrm{CR}$ & $\mathrm{VU}$ \\
Lista vermelha - Minas Gerais & $\mathrm{CR}$ & $\mathrm{VU}$ \\
Lista vermelha - São Paulo & $\mathrm{CR}$ & VU \\
Lista vermelha - Rio de Janeiro & $\mathrm{CR}$ & VU \\
Lista vermelha - Espírito Santo & $\mathrm{CR}$ & $\mathrm{EN}$ \\
Lista vermelha - Pará & $\mathrm{VU}$ & $\mathrm{VU}$ \\
\hline
\end{tabular}

$\mathrm{Na}$ Amazônia Central, a imensa área de floresta contínua favorece a permanência de populações de onças. Abates sistemáticos já levaram à diminuição das populações de onças-pintadas quando o comércio do couro desses animais era permitido (Smith, 1976). A partir da década de 70, a interrupção do comércio de couro e a criação de Unidades de Conservação permitiram que a espécie se recuperasse da baixa populacional. Apesar das onças continuarem sendo abatidas, a densidade estimada é alta nas RDS Mamirauá e Amanã (Ramalho, 2012; Rocha et al., 2012), chegando a uma densidade média de 17,8 indivíduos de onça-pintada por $100 \mathrm{~km}^{2}$ entre os anos de 2005 e 2010.

As onças, na sua esfera "política", têm representantes que as protegem, ao menos por lei, de qualquer tipo de ameaça. Seus direitos são defendidos por legisladores, ambientalistas, ONGs e grande parte da opinião pública. Já as onças enquanto animais de vida livre reivindicam para si apenas ocupar uma área que provenha suas necessidades, o que inclui, entre outras atividades, matar outros animais para se alimentar. Animais domésticos criados em áreas ocupadas por onças acabam incluídos na dieta.

"Perigosa. É sagaz e traiçoeira. Vem perto da gente que ninguém nem dá fé da pisada dela. Ela é tão macia que ela foge e ninguém vê pra onde ela foi" (comunicação pessoal, 2012). Onças são frequentemente "acusadas" de traiçoeiras pelos ribeirinhos e são comparadas a fantasmas porque surgem sem que se perceba a aproximação, como na citação acima. Isso faz parte do repertório de ações das onças, que têm por estratégia estar "invisível" para suas presas até o momento do ataque. As onças são caçadoras eficientes e astutas, mesmo tendo de forma geral um comportamento elusivo em relação ao homem, consegue se aproximar com discrição de moradias em busca de animais domésticos. Além dos problemas de predação de animais domésticos, as onças geram medo e apreensão entre ribeirinhos. Onças são capazes de empreender um ataque contra uma pessoa, e algumas vezes o fazem. Felizmente, ataques contra pessoas são acontecimentos raros.

Embora seja comum para os ribeirinhos se depararem com vestígios de onças, como pegadas, arranhões em árvores, carcaças de presas, fezes e esturros, os encontros com as onças não são tão comuns. Eles dizem que "as onças estão sempre vendo a gente, mas a gente não enxerga elas". Esses animais têm por comportamento padrão se afastar de humanos. Mas algumas onças fogem a esse padrão e parecem não se importar com a presença humana. Outras, talvez pela habituação à predação de animais domésticos, se aproximam deliberadamente das habitações.

As predações de animais domésticos por onças podem ser classificadas em ocasionais e recorrentes. Predações ocasionais, de maneira geral, ocorrem longe de habitações humanas, são espaçadas no tempo, não necessariamente envolvem uma mesma onça e podem ser evitadas com medidas de manejo que mantenham a criação protegida. Já as predações recorrentes, em geral, são causadas por um mesmo indivíduo (chamado de animal-problema) que cria o hábito de se alimentar de animais domésticos. Essas onças tendem a perder o medo de se aproximar de habitações humanas. Causam prejuízos consideráveis, já que as predações são frequentes, e as medidas para proteger a criação de ataques podem não ser eficazes. É claro que as duas situações expostas, a predação ocasional e a recorrente, ocorrem num continuum que vai dos animais com comportamento arisco ao destemido. A aproximação de onças provoca sensação de insegurança entre os ribeirinhos. As comunidades em 
geral só têm luz elétrica nas primeiras horas da noite e a maior parte das casas não tem banheiro, de modo que encontrar pegadas de onças ou animais abatidos em torno das casas é desconfortável para os moradores, uma vez que essa proximidade aumenta o risco de um ataque.

\subsection{Os animais domésticos}

Animais domésticos nas RDS Mamirauá e Amanã incluem porcos, carneiros, bois, búfalos, galinhas, patos, cães, gatos e eventualmente animais silvestres domesticados, como macacos e papagaios. Os rebanhos são familiares e, em geral, compostos por poucas cabeças. Os animais são criados para subsistência e venda, com exceção dos bois e búfalos, que são mantidos como reserva monetária e raramente são abatidos para consumo (Rodrigues et al., 2013).

A maior parte é criada de forma extensiva, andam livres e ocasionalmente adentram a floresta. Há um trade-off na questão de manter os animais soltos: se por um lado o criador tem mais chance de perder os animais por predação, fuga, afogamento, roubo, etc., por outro a preocupação com a alimentação e gastos com instalações são mínimos. A maior parte dos criadores escolhe manter os animais soltos. Como relatou um morador e criador de patos e galinhas: "Quem disser aqui que é criador tá mentindo, aqui ninguém cria bicho não, os bichos que se criam sozinhos. O pessoal quer garantir o rancho, quer ter lucro, mas não quer ter trabalho" (comunicação pessoal, 2011). Os porcos, bois e búfalos costumam se afastar mais das residências em busca de alimento e com frequência entram na floresta. Carneiros, galinhas, patos e gatos têm o hábito de se manter nas imediações das casas. Cães costumam acompanhar as pessoas nas suas atividades cotidianas, são considerados importantes para a caça de animais silvestres e para a proteção das pessoas quando estão andando na floresta.

Os ribeirinhos afirmam que animais domésticos, em especial os porcos, atraem onças. Isso não é, claro, uma ação voluntária. A ação dos animais domésticos está ligada ao manejo que seus proprietários adotam. É comum que esse manejo seja mínimo e que os animais tenham acesso livre a áreas afastadas das comunidades e florestadas. Isso acaba desencadeando a ação das onças contra os animais domésticos e dos ribeirinhos contra as onças. Da mesma forma que as onças costumam seguir varas de queixadas (Tayassu pecari), para atacar indivíduos que se distanciem do bando, é possível que os porcos, ao andar pela floresta de dia e retornar para a comunidade à noite, levem onças no seu encalço. São comuns casos de animais domésticos atacados por onça nas comunidades, a poucos metros das casas.

Animais domésticos são importantes protagonistas na relação gente-onças e existem esforços sendo feitos por gestores/pesquisadores/conservacionistas no mundo inteiro para desenvolver técnicas de manejo que os deixem mais protegidos de predadores silvestres. Embora grandes avanços tenham sido alcançados e vários manuais publicados (Hoogesteijn \& Hoogesteijn, 2005; Marchini et al., 2011), o sucesso dessas iniciativas depende de levar em consideração características locais, como o tipo de ambiente, práticas de produção e manejo, escala e tipo de conflito com a fauna silvestre, assim como particularidades sociais, culturais e econômicas. Os manuais publicados no Brasil para proteger criações domésticas de onças foram feitos para grandes e médios criadores de gado e pouco pode ser aplicado na realidade ribeirinha. Estudos em comunidades rurais com características mais próximas aos ribeirinhos amazônicos foram feitos com resultados promissores em diversos países (Ogada et al., 2003; Marker et al., 2005; Lamarque et al., 2008), mas as diferenças culturais, de práticas de manejo e de escala do conflito tornam difíceis a sua aplicabilidade. Por isso, as técnicas para proteger esses animais devem surgir da observação in loco do seu manejo e, principalmente, da participação e do protagonismo dos seus criadores.

\subsection{Modos de produção}

A produção econômica nas reservas é tipicamente camponesa, caracterizada pela combinação de uma produção doméstica para consumo direto e para venda (Peralta et al., 2008). Benefícios sociais respondem a mais de $50 \%$ da fonte de renda doméstica (Stremel et al., 2012).

A agricultura, com destaque para o cultivo da mandioca para a produção de farinha, e a pesca são as principais atividades produtivas e a base da alimenta- 
ção, sendo que a atividade produtiva que predomina como fonte de renda nas comunidades de terra firme é a agricultura, enquanto a pesca é predominante nas comunidades de várzea. A criação de animais domésticos complementa a renda e garante proteína animal em períodos de escassez na pesca e na caça. Também há usos tradicionais, como, por exemplo, os porcos criados para consumo nos festejos de santos, as galinhas criadas para o resguardo das mulheres grávidas ou os bezerros criados para servir de prêmio de torneios de futebol. Atividades extrativistas também são importantes para subsistência e complementação de renda, com destaque para a coleta de castanha e açaí.

Os órgão gestores das RDS Mamirauá e Amanã (IDSM e CEUC) desenvolvem junto aos ribeirinhos estratégias de geração de renda sustentáveis. O manejo do pirarucu (Arapaima gigas) é o mais emblemático exemplo, que também inclui manejo de peixes ornamentais, manejo de produtos florestais madeireiros e não madeireiros, turismo de base comunitária, granjas comunitárias, meliponicultura e difusão de técnicas agroecológicas. O sucesso dessas alternativas de renda e manejo dos recursos naturais depende de pesquisas sobre sua viabilidade e envolvimento dos ribeirinhos, seja no âmbito familiar, comunitário ou setorial. Algumas dessas alternativas prosperam e outras não.

Para pescar, cultivar a roça, extrair produtos florestais e caçar, o ribeirinho precisa normalmente entrar na floresta, seja por trilhas, igarapés ou igapós. São comuns os relatos de encontros com onças nessas ocasiões.

\subsection{A paisagem}

A RDS Mamirauá é inteiramente formada por ecossistema de várzea, enquanto Amanã apresenta áreas de várzea e terra firme. As principais fitofisionomias florestais desses ecossistemas são matas de terra firme, matas de igapó, chavascal, restinga alta e restinga baixa (Ayres, 1995). Além das florestas, há um grande número de habitats aquáticos que podem ser perenes ou temporários, como lagos, rios, igarapés, canais, paranás, furos, poças e as próprias formações florestais sazonalmente alagadas. A variação do nível da água promove uma intensa e contínua modificação nos habitats aquáticos e terrestres. Dentro desse mosaico fluido de ambientes aquáticos e terrestres, a intensidade de uso da paisagem por onças e ribeirinhos não é homogênea e depende do alagamento sazonal.

Os ribeirinhos procuram construir suas casas e plantar suas roças em áreas altas. As casas são dispostas uma ao lado da outra, de frente para um corpo d'água (rio, lago ou canal) e de fundos para a floresta. Em geral, as comunidades possuem escola, centro comunitário, igreja e campo de futebol. Fazem parte também da área de uso dos ribeirinhos o campo (onde pastam os animais), o sítio (onde plantam árvores frutíferas e temperos), a casa de farinha, o roçado, os lagos de pesca, as trilhas que ligam as comunidades aos lagos e roçados e as áreas de caça e extrativismo. As atividades produtivas também variam com a mudança no nível da água.

Na paisagem, alguns locais se destacam, de acordo com os ribeirinhos, como áreas de interseção de uso por onças e pessoas. Pescadores afirmam ser comum encontrar onças andando nas margens dos lagos no período da seca, à procura de jacarés e seus ninhos, e em galhos de árvores na mata alagada no período da cheia. As trilhas que ligam as comunidades aos roçados e lagos são também frequentemente usadas por onças, e ribeirinhos relatam que elas têm o hábito de "rastejá-los" nessas trilhas. Eles chamam de rastejar quando onças seguem seus rastros: eles passam pela trilha e quando retornam encontram as pegadas da onça marcando todo o caminho. É um hábito comum entre os felinos usar trilhas para se locomover (Silver et al., 2004). Outra área de interseção são as próprias comunidades, onde por vezes as onças adentram à procura da criação doméstica. São muitos os relatos de avistamentos, marcas de pegadas e ataques a animais na área das comunidades.

\subsection{A legislação}

No Brasil, o Decreto Lei ${ }^{\circ} 24.645$, de 10 de julho de 1934 , estabeleceu em seu art. $1^{\circ}$ que todos os animais existentes no país são tutelados pelo Estado. $\mathrm{O}$ art. 13 previa penas para o abate de animais com a ressalva de que não se tratasse de "animal feroz ou atacado de moléstia perigosa". Embora defina no art. 17 que considera como animal "todo ser irracional, quadrúpede ou bípede, 
doméstico ou selvagem, exceto os daninhos", o Decreto dá ênfase à proteção de animais domésticos. É interessante notar que os termos "animais ferozes" e "animais daninhos" poderiam ser aplicados aos carnívoros que causam prejuízos às criações animais.

Em 1967, foi promulgada a Lei de Proteção à Fauna (Lei no 5.197, de 03 de janeiro de 1967), que trata especificamente da fauna silvestre e proíbe sua utilização, perseguição, destruição, caça ou apanha. A Lei menciona permissões especiais para a caça, como nos casos de coletas científicas, clubes de caça esportiva e peculiaridades regionais, desde que devidamente licenciadas por autoridade competente. Menciona também no art. $3^{\circ}, \S 2^{\circ}$ que, mediante licença de autoridade competente, é permitida a "destruição de animais silvestres considerados nocivos à agricultura ou à saúde pública". Não faz menção aos animais silvestres que causam danos às criações de animais domésticos.

Na segunda metade do século XX, o Brasil se tornou signatário de várias convenções internacionais de proteção à natureza, com destaque para a Convenção sobre o Comércio Internacional das Espécies da Flora e Fauna Selvagens em Perigo de Extinção (CITES), firmada em Washington, em 3 de março 1973.

A Constituição Brasileira (Brasil, 1998), promulgada em cinco de outubro de 1988, faz referência às questões ambientais em seu art. 225 , cujo $\S 1^{\circ}$, VII, determina como responsabilidade do Poder Público "proteger a fauna e a flora, vedadas, na forma da lei, as práticas que coloquem em risco sua função ecológica, provoquem a extinção das espécies ou submetam os animais a crueldade". Não menciona exceções para o abate de animais silvestres.

A Constituição do Estado do Amazonas, de cinco de outubro de 1989, em seu Capítulo XI, trata das questões ambientais e no art. 230, VIII, incumbe ao Estado e Municípios a mesma responsabilidade citada no parágrafo acima, e também não faz menção às exceções para a proibição ao abate da fauna ou à proteção de rebanhos domésticos da ação predatória de animais silvestres.

Em 1998, com o advento da Lei de Crimes Ambientais (Lei 9.605, de 12 de fevereiro de 1998), as exceções para a proibição ao abate de animais silvestres foram tratadas no art. 37, transcrito a seguir:
Art. 37. Não é crime o abate de animal, quando realizado: I - em estado de necessidade, para saciar a fome do agente ou de sua família;

II - para proteger lavouras, pomares e rebanhos da ação predatória ou destruidora de animais, desde que legal e expressamente autorizado pela autoridade competente; III - em legítima defesa, diante do ataque de animais ferozes (VETADO);

IV - por ser nocivo o animal, desde que assim caracterizado pelo órgão competente.

A legítima defesa, prevista no art. 37, III, foi vetada segundo as seguintes razões:

\begin{abstract}
"O instituto de legítima defesa pressupõe a repulsa a agressão injusta, ou seja, intenção de produzir o dano. Por isso, na síntese lapidar de Celso Delmato, 'só há legítima defesa contra agressão humana, enquanto que o estado de necessidade pode decorrer de qualquer causa.' No caso, a hipótese de que trata o dispositivo é configurada no artigo 24 do Código Penal."
\end{abstract}

O inciso III foi vetado por uma questão de semântica, mas o abate no caso de ataque de animal silvestre é previsto com base no art. 24 do Código Penal: "Considera-se em estado de necessidade quem pratica o fato para salvar de perigo atual, que não provocou por sua vontade, nem podia de outro modo evitar, direito próprio ou alheio, cujo sacrifício, nas circunstâncias, não era razoável exigir-se."

$\mathrm{O}$ art. 37, II, prevê situações de conflitos entre predadores e animais domésticos e permite o abate do predador desde que autorizado pela autoridade competente. No entanto o art. 37, II, nunca foi regulamentado ou aplicado (Macedo, 2015). A lei não especifica quem é a autoridade competente para julgar a pertinência de pedidos de autorização de abate, nem tampouco define "animal nocivo" ou "feroz". O que se conclui é que a lei prevê o conflito com a fauna e resguarda o prejudicado pelo conflito, mas, na prática, o prejudicado não sabe a quem recorrer e ainda está sujeito a interpretações de quem autoriza abates ou define o que é "perigo" ou "animal nocivo". Embora os ribeirinhos saibam que é proibido abater onças, eles desconhecem as exceções para a proibição em casos de ataques a rebanhos e a pessoas. 


\subsection{Representantes de órgãos ambientais e pesquisadores}

Representantes de órgãos ambientais são funcionários do Instituto Chico Mendes de Conservação da Biodiversidade (ICMBio), do Instituto Brasileiro de Meio Ambiente e dos Recursos Naturais Renováveis (IBAMA), do Centro Estadual de Unidades de Conservação (CEUC/SDS) e do Instituto de Proteção Ambiental do Estado do Amazonas (IPAAM). Já os pesquisadores que compõem a rede incluem aqueles que trabalham no Instituto de Desenvolvimento Sustentável Mamirauá (IDSM) e atuam na área das RDS Mamirauá e Amanã em diversas linhas de pesquisa e têm contato direto com os ribeirinhos, além daqueles que trabalham com conservação de onças e se debruçam sobre o conflito com produtores rurais.

Os representantes de órgãos ambientais e pesquisadores que trabalham na Amazônia tendem a compreender e demonstrar empatia para com os problemas advindos da relação entre ribeirinhos e onças. Ainda que defendam as onças, costumam entender os motivos dos ribeirinhos. Já os que não trabalham diretamente com populações ribeirinhas tendem a ter dificuldade para entender o problema e visualizar o cotidiano real de homens e onças nas florestas e costumam tratar o tema de forma maniqueísta (onças boas $\mathrm{x}$ homens maus). Talvez por não terem conhecimento sobre o modo de vida dos ribeirinhos e a dinâmica que envolve o conflito, é comum acusá-los de não protegerem adequadamente suas criações e abaterem as onças em retaliação a um problema criado por eles próprios pelo manejo deficiente dos animais. Os mais puristas consideram um erro permitir que populações tradicionais criem animais domésticos dentro de UCs de Uso Sustentável, em função dos danos que esses animais podem causar à vida silvestre e à paisagem.

A formação em ciências naturais ou ciências sociais também tende a influenciar a abordagem que esses atores dão ao conflito com a fauna. Cientistas naturais em geral não recebem em sua formação noções de ferramentas e métodos para tratar questões sociais e políticas, assim como aos cientistas sociais faltam elementos técnicos para tratar com propriedade sobre ecologia e conservação. Com a emergência de problemas socioambientais, como o conflito com a fauna, esses profissionais precisam desenvolver habilidades e sensibilidades para que a abordagem seja interdisciplinar. Além do desafio da interdisciplinaridade, o conflito entre onças e ribeirinhos é um tema que desperta paixões subjetivas e nem todos são capazes de examiná-lo despidos de seus preconceitos.

Apesar de os atritos entre onças e moradores serem frequentes nas RDS Mamirauá e Amanã, as demandas por soluções não chegam aos representantes de órgãos ambientais (embora cheguem para os pesquisadores do IDSM). Mesmo considerando o Estado do Amazonas, poucas queixas sobre predação de animais domésticos por onças foram registradas em órgãos ambientais (Macedo, 2015). Isso provavelmente é reflexo das longas distâncias e dificuldades de comunicação e, principalmente, da associação que os ribeirinhos fazem entre órgãos ambientais e fiscalização e multas.

Os órgãos ambientais agem de acordo com a legislação no que tange à conservação de onças, mas, por falta de estrutura e recursos humanos e das vastas extensões territoriais e dificuldade de locomoção, são deficientes na fiscalização de crimes ambientais. Já os pesquisadores que têm como tema de estudo as onças estão em geral focados em gerar conhecimentos que subsidiem estratégias de conservação. As pesquisas incluem estimativas de abundância populacional, uso do hábitat, dieta, conflitos com produtores rurais, entre outros temas. Usam técnicas e instrumentos para acessar informações, como armadilhas fotográficas, colares com GPS que enviam a localização dos animais via satélite, programas que calculam viabilidade populacional, variabilidade genética, etc. $\mathrm{O}$ avanço das técnicas permitiu um salto no conhecimento sobre onças de vida livre. $\mathrm{Na}$ RDS Mamirauá, por exemplo, armadilhas fotográficas permitiram a estimativa de uma alta densidade populacional de onça-pintada, uma das mais altas descritas para a espécie, corroborando a impressão dos ribeirinhos sobre o número de animais. E, ainda, onças-pintadas equipadas com rádio-colares (Figura 2) permitiram confirmar cientificamente que estas passam a época da cheia em Mamirauá em cima das árvores, fato já amplamente conhecido pelos moradores locais.

Há uma série de afirmações (sem entrar no mérito se procedem ou não) que são feitas comumente por técnicos de órgãos ambientais e pesquisadores para dis- 


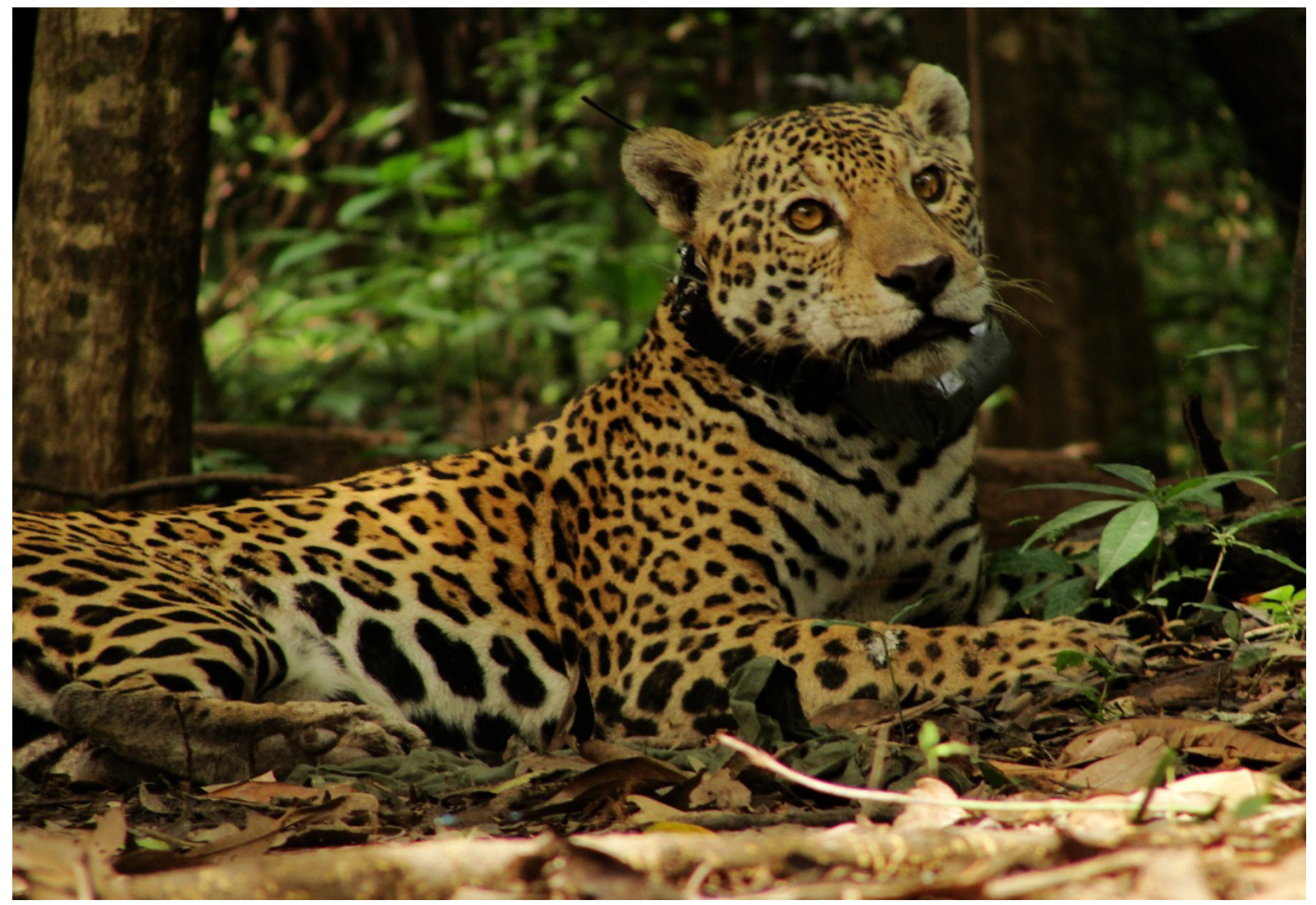

FIGURA 2 - Onça-pintada, floresta, homens, ciência, tecnologia, satélites e ondas de rádio. Onça Jandiá (nome dado pelos pesquisadores) nos arredores do Lago Mamirauá voltando da anestesia após ser equipada com colar de radiotelemetria e GPS. Fotografia: Joana Macedo.

suadir o abate de onças por produtores rurais. Entre elas: onças estão ameaçadas de extinção; as onças já viviam aqui antes dos homens invadirem seus territórios; matar onças é crime inafiançável; onças estão se aproximando de habitações humanas porque o homem destruiu seu habitat natural; onças matam animais domésticos porque o homem acabou com os animais silvestres que elas predavam naturalmente; onças só atacam reincidentemente animais domésticos se estiverem debilitadas por algum motivo, como injúrias provocadas por tiro ou armadilha, que impedem que elas tenham habilidade para capturar presas silvestres; onças atacam criações domésticas quando o proprietário não toma as devidas precauções para proteger seus animais; onças aprendem a se alimen- tar de animais domésticos quando os proprietários, ao invés de enterrar, deixam as carcaças dos animais mortos na mata; as perdas provocadas pelos ataques de onça aos rebanhos domésticos são inferiores a perdas provocadas por outros fatores relacionados ao manejo deficiente; onças não atacam pessoas se não forem acuadas ou feridas por estas. Essas afirmações em geral procuram eximir as onças de "culpa" e transferi-la para os homens. É uma perspectiva que reflete de modo geral uma visão urbana, conservacionista, acadêmica e até romântica do problema enfrentado pelos criadores e não considera as peculiaridades de cada caso, que incluem, entre outros fatores, o modo de existência, situação econômica, segurança, crenças, medos e valores. 


\subsection{Opinião pública}

É um grupo grande, heterogêneo e de difícil definição. Onças são animais que geram um forte apelo para a causa ambientalista. Estão estampando uma parte significativa de campanhas em prol da conservação. Documentários também retratam com frequência onças e pesquisadores empenhados em protegê-las. Todo esse marketing faz com que a opinião pública se posicione em favor desses animais e condene abates com veemência. A posição da opinião pública tem grande importância para a conservação, já que influencia comportamentos em favor da causa via apelo à norma social (Fernandes-Ferreira \& Alves, 2014).

Os ribeirinhos têm ciência da posição da opinião pública e se sentem injustiçados, já que acreditam que qualquer pessoa reagiria a um animal que ameaçasse a segurança da sua família. E dizem que morar na cidade grande e defender as onças é fácil, difícil é conviver com elas.

A opinião pública urbana ocidental condena maus-tratos e mortes de animais com os quais não têm nenhuma proximidade física ou convivência cotidiana (Descola, 1998). Animais carismáticos são alvo frequente dessa empatia e a defesa deles muitas vezes não leva em conta o contexto em que estão inseridos. E no contexto se encontram detalhes que informam sobre o grau de ameaça que os animais sofrem, suas principais fontes, os danos da convivência com eles e eventuais usos tradicionais. Por exemplo, o uso de casacos de pele de urso pode não fazer sentido na São Paulo Fashion Week e fazer sentido na Sibéria. Do mesmo modo, os esforços para conservação da onça-pintada na Mata Atlântica podem não fazer sentido no contexto amazônico.

\section{Discussão}

\subsection{Qual é a natureza das ações?}

As ações são fomentadas pelos elementos mais diversos, não necessariamente presentes, racionais ou óbvios. Segundo Latour (2012), "na maioria das situações, as ações são afetadas por entidades heterogêneas que não têm a mesma presença local, não se originam na mesma época, não são imediatamente visíveis e não as pressionam com o mesmo peso".

As onças não existem apenas ao encontrar humanos e seus animais domésticos, têm uma existência biológica, ecológica, simbólica e política que ultrapassa em muito a relação com os povos da floresta. As controvérsias nos discursos sobre o animal deixam claro que o termo "onça" faz referência a diferentes construções que vão além dos limites do animal em si.

As interações entre ribeirinhos, onças e animais domésticos têm uma natureza concreta nos encontros, abates, predações, fugas e ataques. São momentos onde a ação está em primeiro plano e decisões imediatas precisam ser tomadas.

Por mais imediatas e até instintivas que sejam as ações durante as interações diretas, elas têm também uma natureza política. No momento da ação, fatores como a aprovação ou reprovação dos vizinhos e familiares, as regras do plano de gestão da UC, a legislação ambiental e até as reportagens da TV estão exercendo uma influência política.

Além da natureza concreta e política, também está presente na ação o imaginário. Na ação, histórias de antepassados, mitos e a cosmologia que envolve as onças vêm à tona. Pessoas que se transformam em onças, onças encantadas, poderes sobrenaturais, espécies de onças nunca descritas, tudo isso faz parte do imaginário que envolve as onças e exerce influência nas ações.

Já as ações para conservação das onças têm por base um repertório técnico-científico que envolve técnicas sofisticadas e uma rede de cientistas que se dedicam ao tema. No contexto da conservação, os abates de onças devem ser evitados a todo custo, e para isso pesquisas são desenvolvidas no intuito de proteger as onças de produtores rurais e proteger as criações domésticas do ataque de onças. A política é posta em movimento, mas não de forma democrática, uma vez que em geral apenas o conhecimento técnico é apresentado como solução para os problemas de convivência.

Para além da ciência, há uma dose de subjetividade envolvendo a conservação de onças que perpassa desde a construção do conhecimento científico até o ativismo ambientalista. $\mathrm{O}$ simbolismo desses animais não deve ser ignorado, esteve presente nas sociedades 
pré-colombianas, está presente nas sociedades indígenas e "modernas". Ora como encantados (Kohn, 2013), ora como estrelas de campanhas publicitárias em prol da conservação, estão sem dúvida exercendo influência. E o conhecimento científico gerado em torno do tema onça não é imune a esse simbolismo. Questões de fato e questões de valor se embaralham também em um fazer científico que curiosamente pretende oferecer o fato para livrar da crença. Latour (2001) discorre sobre como a Ciência ${ }^{9}$ tomada como verdade estabilizada acaba apresentando características de crença, como na passagem abaixo:

Os fatos foram longe demais, tentando transformar tudo o mais em crenças. O fardo de todas essas crenças torna-se insuportável quando, como na categoria pós-moderna, a própria ciência é submetida à mesma dúvida. Uma coisa é atacar as crenças quando estamos fortificados pelas certezas da ciência. Mas que devemos fazer quando a própria ciência se transforma numa crença? (Latour, 2001).

\subsection{Como tratar de forma democrática a rede do conflito?}

Primeiro, é preciso identificar as principais controvérsias da rede e expô-las de forma simétrica. Isso porque a deficiência no diálogo entre ribeirinhos e profissionais que trabalham com conservação, sintoma da assimetria, tem como efeito colateral aprofundar o conflito. Populações afetadas por conflitos com a fauna apoiam estratégias de conservação na medida em que seus problemas são considerados e suas reivindicações atendidas. Do contrário, exercem o efeito oposto ao esperado e qualquer tema relacionado à conservação possa a ser mal visto (Linnell, 2015). Portanto, é importante que pesquisadores e gestores exercitem a política nas suas práticas. Sem estabelecer um diálogo simétrico e um entendimento honesto das circunstâncias locais, dificilmente se alcançam os objetivos propostos para a conservação.

A principal controvérsia no caso em questão trata do conflito de interesses entre os atores humanos. Preocupações locais com segurança, subsistência e perdas econômicas entram em embate com preocupações internacionais com a conservação de espécies ameaçadas. A relação entre onças e povos da floresta, que pode ser resumida como uma competição (na acepção ecológica da palavra) por espaço e recursos, é agora mediada por leis, estratégias de conservação e uma opinião pública preservacionista. A despeito das leis, essa competição continua resultando em abates de onças em retaliação aos danos causados pela convivência com esse animal. Mas agora o ribeirinho está infringindo a lei e, portanto, sujeito às suas penas, e é condenado e estigmatizado por seus atos.

Para se estabelecer um cenário democrático, a construção do conhecimento sobre o tema deve se dar em conjunto entre as partes divergentes, deixando as representações de fora da mesa de negociações. Ao buscar soluções para o conflito, o conhecimento científico e os medos e angústias dos ribeirinhos devem estar em um mesmo plano. Afinal, conhecer a probabilidade estatística de ser atacado por uma onça não faz com que o medo de um ataque desapareça. Hurn (2009) apresentou alguns exemplos de estudos que demonstraram que o medo de grandes felinos é desproporcional aos casos de ataques, mas ressaltou que "meros fatos não podem competir com a percepção". Partindo do princípio de que "o real não é indiscutível, o fato é controvertido e fabricado coletivamente" (Latour, 2012), a construção do mundo comum deve ser negociada e acordada entre as partes, de forma democrática. De modo que, eventualmente, fatos científicos podem ser postos em cheque e o imaginário sobre onças pode ser considerado.

Portanto, para pôr em movimento essas práticas é preciso que os ribeirinhos estabeleçam um canal de comunicação com os demais atores humanos que compõem a rede e que os profissionais da conservação tomem ciência da importância do diálogo simétrico e

\footnotetext{
${ }^{9}$ Latour faz uma distinção entre Ciência com C maiúsculo e ciências, onde a primeira representa, entre outras coisas, a Ciência como uma verdade pronta e aceita por seus seguidores, enquanto a segunda representa o conhecimento em construção, com todas as suas controvérsias.
} 
procurem estar qualificados para incorporar a política nas suas ações. Não uma política impregnada da concepção moderna ocidental, subsidiada por verdades científicas estabelecidas a priori, mas antes uma política democrática, que consulte os envolvidos a despeito de seu aparato de leitura do mundo. Ou, como pontuou Viveiros de Castro (2007), "uma boa política é aquela que multiplica os possíveis, que aumenta o número de possibilidades".

O protagonismo das populações afetadas e o enfoque interdisciplinar dos cientistas aproximam as iniciativas do tratamento democrático do conflito com a fauna. Um importante passo a ser dado para a construção do mundo comum é a incorporação pelos pesquisadores brasileiros das práticas de mitigação e manejo de conflitos já adotadas em outros países e que podem facilmente ser acessadas pelas publicações de diversos grupos de

\section{Referências}

Amâncio, C.; Crawshaw Jr., P.; Tomas, W.; Rodrigues, R.; Silva, M. V. Understanding local populations to facilitate jaguar conservation in Brazil. In: Anais do V Congresso Brasileiro de Unidades de Conservação. Curitiba: Fundação O Boticário de Proteção à Natureza \& IPEF, 35, 41-46, 2007.

Amazonas. Constituição do Estado do Amazonas, de 5 de outubro de 1989. DOE de 5/10/1989.

Ayres, J. M. As matas de várzea de Mamirauá. Brasília: MCT-CNPq-PTU/Sociedade Civil Mamirauá, 1995.

Blandin, B. La construction du social par les objets. Paris: Presses Universitaires de France, 2002. doi: 10.3917/puf. bland.2002.01.

Brasil. Decreto Lei n. 24.645, de 10 de julho de 1934. Estabelece medidas de proteção aos animais. DOU de 13/07/1948.

Brasil. Lei de Proteção à Fauna, n. 5.197, de 03 de janeiro de 1967. Dispõe sobre a proteção à fauna e dá outras providências. DOU de 5/01/1967.

Brasil. Constituição da República Federativa do Brasil, de 5 de outubro de 1988. 11. ed. São Paulo, Atlas, 1998.

Brasil. Lei de Crimes Ambientais, Lei 9.605, de 12 de fevereiro de 1998. Dispõe sobre as sanções penais e administrativas derivadas de condutas e atividades lesivas ao meio ambiente, e dá outras providências. DOU de 13/02/1998. pesquisa envolvidos com esse tema (como, por exemplo: Treves \& Karanth, 2003; Madden, 2004; Treves et al., 2006; Dickman, 2010). Para tanto, é preciso substituir a Ciência pelas ciências.

Dada a complexidade do conflito com a fauna, fica claro que o sucesso na abordagem do tema não depende apenas de questões ecológicas, biológicas e técnicas, mas também de questões sociais, culturais, políticas e econômicas. É importante entender o ponto de vista de todos os envolvidos de alguma forma nos conflitos, incluindo os atores não-humanos, e ser capaz de considerar e entender crenças, medos, atitudes e necessidades, e assumir que as onças podem ser simultaneamente ameaça e ameaçadas. Sem considerar essa dimensão do problema, não há como promover a conservação de felinos e diminuir os riscos às populações humanas.
Callon, M.; Lascoumes, P.; Barthe, Y. Agir dans un monde incertain. Essai sur la démocratie technique. Paris: Le Seuil. 2001.

Castro, F.; Siqueira A.; Brondízio, E. S.; Ferreira, L. C. Use and misuse of the concepts of tradition and property rights in the conservation of natural resources in the atlantic forest (Brazil). Ambiente \& Sociedade, 9(1), 23-39, 2006. Disponível em: $<$ http://www.scielo.br/pdf/asoc/v9n1/a02v9n1.pdf $>$.

Descola, P. Estrutura ou sentimento: a relação com o animal na Amazônia. Mana, 4, 23-45, 1998. doi: 10.1590/S010493131998000100002.

Dickman, A. Complexities of conflict: the importance of considering social factors for effectively resolving humanwildlife conflict. Animal Conservation, 13, 458-466, 2010. doi:10.1111/j.1469-1795.2010.00368.x.

Fernandes-Ferreira, H.; Alves, R. R. N. Legislação e mídia envolvendo a caça de animais silvestres no Brasil: uma perspectiva histórica e socioambiental. Gaia Scientia, 8(1), 1-7, 2014. Disponível em: <http://periodicos.ufpb.br/ojs2/index. $\mathrm{php} / \mathrm{gaia} /$ index $>$.

Hoogesteijn, R.; Hoogesteijn, A. L. Manual sobre os problemas de predação causados por onças-pintadas e onças-pardas em fazendas de gado. New York: Wildlife Conservation Society, 2005. Disponível em: <www.panthera.org/sites/default/files/ JaguarDepredationManualPORTUGUESE.pdf $>$. 
Hurn, S. Here be dragons? No, big cats! Predator symbolism in rural West Wales. Anthropology Today, 25(1), 6-11, 2009. doi:10.1111/j.1467-8322.2009.00640.x.

Inskip, C.; Zimmermann, A. Human-felid conflict: a review of patterns and priorities worldwide. Oryx, 43, 18-34, 2009.

IUCN - International Union for Conservation of Nature. IUCN Red List Categories and Criteria: Version 3.1. Second edition. Gland, Switzerland and Cambridge, UK: IUCN, iv, 2012. Disponível em: <http://www.iucnredlist.org/technical-documents/categories-and-criteria/2001-categories-criteria>. Acesso em: 02 mar. 2015.

Kohn, E. How forests think: toward as Anthropology beyond the human. California: University of California Press, 2013. Disponível em: <http://www.anth.ucsb.edu/sites/secure.lsit. ucsb.edu.anth.d7/files/sitefiles/Kohn\%20-\%20How\%20Forests\%20Think\%20-\%20Introduction.pdf>.

Krithivasan, R.; Athreya, V.; Odden, M. Human-Wolf Conflict in Human Dominated Landscapes of Ahmednagar District, Maharashtra, and possible mitigation measures. Report to the Rufford Small Grants Foundation, 2009. Disponível em: $<$ http://www.projectwaghoba.in/docs/roopa_krithivasan_indian_wolf_report_2009.pdf>

Kruuk H. Hunter and Hunted: Relationships Between Carnivores and People. Cambridge: Cambridge University Press, 2002.

Lamarque, F.; Anderson, J.; Chardonnet, P.; Fergusson, R.; Lagrange, M.; Osei-Owusu, Y.; Bakker, L.; Belemsobgo, U.; Beytell, B.; Boulet, H.; Soto, B.; Tabi Tako-Eta, P. HumanWildlifeConflict in Africa. An overview of causes, consequences and management strategies. Rome: International Foundation for the Conservation of Wildlife - Food and Agriculture Organization of the United Nations, 2008. Disponível em: <http://www.fao.org/docrep/012/i1048e/i1048e00.htm>.

Latour, B. La clef de Berlin et autres leçons d'un amateur de sciences. Paris: La Découverte, 1993.

Latour, B. Jamais fomos modernos: ensaio de antropologia simétrica. Rio de Janeiro: Ed. 34, 1994.

Latour, B. Politiques de la nature. Comment faire entrer les sciences en démocratie. Paris: La Découverte, 1999.

Latour, B. A Esperança de Pandora: ensaios sobre a realidade dos estudos científicos. Bauru: EDUSC, 2001.

Latour, B. Reagregando o social: uma introdução à teoria do Ator-Rede. Salvador: Edufba, 2012.
Lima-Ayres, D. The social category caboclo: history, social organization, identity and outsider's social classification of the rural population of an Amazonian region (the middle Solimões). Cambridge, Tese (Doutorado em Antropologia Social), University of Cambridge, 1992.

Lima, D.; Alencar, E. F. Histórico da ocupação humana e mobilidade geográfica de assentamentos na Várzea do Médio Solimões. In: Torres, H.; Monteiro, H. (Orgs.). Populações e meio ambiente. Brasília: Associação Brasileira de Estudos Populacionais; São Paulo: Senac, 2000. p. 133-161.

Linnell, J. From conflict to coexistence: Insights from multidisciplinary research into the relationships between people, large carnivores and institutions. Istituto di Ecologia Applicata with the assistance of the Norwegian Institute for Nature Research/IUCN/SSC Large Carnivore Initiative for Europe, 2013. Disponível em: $<$ http://ec.europa.eu/environment/nature/ conservation/species/carnivores/index_en.htm>

Linnell, J. Dialogue to reduce conflicts. Carnivore Damage Prevention, 11, 1-3, 2015. Disponível em: $<$ http://www1.nina. no/lcie_new/pdf/635572572582373699_CDPnews11_Winter2015-Z.pdf>.

Macedo, J. Ameaça ou ameaçada? A relação entre onças (Panthera onca e Puma concolor) e moradores das Reservas de Desenvolvimento Sustentável Mamirauá e Amanã na Amazônia. Rio de Janeiro, Tese (Doutorado em Meio Ambiente) - UERJ, 2015.

Madden, F. Creating Coexistence between Humans and Wildlife: Global Perspectives on Local Efforts to Address Human-Wildlife Conflict. Human Dimensions of Wildlife, 9(4), 247-257, 2004. doi: 10.1080/10871200490505675.

Marchini, S. Human dimensions of the conflicts between people and jaguars (Panthera onca) in Brazil. Oxford, Tese (Doutorado em Zoologia) -University of Oxford, 2010.

Marchini, S.; Cavalcanti, S. M. C.; De Paula, R.; Cunha,R. Predadores silvestres e animais domésticos:guia prático de convivência. Brasília: Instituto Chico Mendes de Conservação da Biodiversidade, 2011.

Marker, L. L.; Dickman, A. J.; MacDonald, D. W. Perceived effectiveness of livestock guarding dogs placed on Namibian farms. Rangeland Ecology \& Manegement, 58, 329-336, 2005. doi: 10.2111/15515028(2005)058[0329:PEOLDP]2.0.CO;2.

McKnight, M. Thylacinus cynocephalus. The IUCN Red List of Threatened Species 2008. doi: 10.2305/IUCN.UK.2008.RLTS. T21866A9332383.en. Acesso em: 07 out. 2015. 
Moura, E.; Nascimento, A. C.; Corrêa, D. S.; Alencar, E.; Sousa, I. S. Sociodemografia da Reserva de Desenvolvimento Sustentável Mamirauá: 2001- 2011. Belém: NAEA/IDSM, 2015.

Ogada, M. O.; Woodroffe, R.; Oguge, N.; Frank, L. G. Limiting depredation by African carnivores: the role of livestock husbandry. Conservation Biology, 17, 1521-1530, 2003.

Peralta, N.; Moura, E.; Nascimento, A. C.; Lima, D. Renda doméstica e sazonalidade em comunidades da RDS Mamirauá, 1995-2005. Uakari, 5(1), 7-19, 2008. Disponível em: <http://www.uakari.org.br/index.php/UAKARI/article/ viewFile/51/64>.

Quammen, D. Monstro de Deus - feras predadoras: história, ciência e mito. São Paulo: Companhia das Letras, 2007.

Ramalho, E. E. Jaguar (Panthera onca) population dynamics, feeding ecology, human induced mortality, and conservation in the várzea floodplain forests of Amazonia. Flórida, Tese (doutorado), Universidade da Florida, 2012.

Redpath S. M.; Gutiérrez R. J.; Wood K. A.; Sidaway R.; Young, J. C. An introduction to conservation conflicts. In: Redpath S. M.; Gutiérrez R. J.; Wood K. A.; Young, J. C (Org.). Conflicts in Conservation: Navigating Towards Solutions. Cambridge: Cambridge University Press, British Ecological Society, 2015.

Rocha, D.; Ramalho, E. E.; Nassar, P. M. Amostragem preliminar da fauna na Reserva de Desenvolvimento Sustentável Amanã com armadilhas fotográficas. In: Livro de Resumos do $9^{\circ}$ Seminário Anual de Pesquisa do Instituto de Desenvolvimento Sustentável Mamirauá. Tefé, 3 jul. 2012.

Rodrigues, L. G.; Richers, B. T. T.; Araújo, A. L. O. Livestock raising in the Amanã Sustainable Development Reserve, Amazonas State. Uakari, 9(1), 7-24, 2013.

Sá,G. No mesmo galho: Antropologia de coletivos humanos e animais. Rio de Janeiro: 7 Letras, 2013.

Sanderson, E. W.; Redford, K. H.; Chetkiewicz, C. B.; Medellin, R. A.; Rabinowitz, R. A.; Robinson, J. G.; Taber, A. B. Planning to save a species: the jaguar as a model. Conservation Biology, 16, 1-15, 2002. doi:10.1046/j.1523-1739.2002.00352.x.

Sillero-Zubiri, C.; Sukumar, R.; Treves, A. Living with wildlife: the roots of conflict and the solutions. In: MacDonald, D.W.;
Service, K. (Orgs.). Key topics in conservation biology. Oxford: Blackwell Publishing, 2006.

Silveira, L. Ecologia comparada da onça-pintada (Panthera onca) e onça-parda (Puma concolor) no Cerrado e Pantanal. Brasília, Tese (Doutorado) - Universidade de Brasília,2004.

Silver, S.; Ostro, L.; Marsh, L.; Maffei, L.; Noss, A.; Kelly, M.; Wallace, R.; Gómez, R.; Ayala, G. The use of camera traps for estimating jaguar Panthera onca abundance and density using capture/recapture analysis. Oryx, 38, 148-154, 2004. doi: $10.1017 / \mathrm{S} 0030605304000286$.

Smith, N. J. H. Spotted cats and the Amazon skin trade. Oryx, 13, 362-371, 1976. doi: 10.1017/S0030605300014095.

Stremel, A.; Peralta, N.; Lima, D. Uma análise socioeconômica da RDSM com base nos indicadores de renda e patrimônio doméstico. Livro de Resumos do $9^{\circ}$ Seminário Anual de Pesquisa do Instituto de Desenvolvimento Sustentável Mamirauá. Tefé: IDSM/CNPq, 03 jul. 2012.

Süssekind, F. $O$ rastro da onça: relações entre humanos e animais no Pantanal. Rio de Janeiro: Editora 7 Letras, 2014.

Treves, A.; Karanth,K. U. Human-carnivore conflict and perspectives on carnivore management worldwide. Conservation Biology, 17(6), 1491-1499, 2003. doi: 10.1111/j.15231739.2003.00059.x.

Treves, A.; Wallace, R. B.; Naughton-Treves, L.; Morales, A. Co-managing human-wildlife conflicts: a review. Human Dimensions of Wildlife, 11(6), 1-14, 2006. doi: 10.1080/10871200600984265.

Valsecchi, J. Caça de animais silvestres nas Reservas de Desenvolvimento Sustentável Mamirauá e Amanã. Belo Horizonte, Tese (Doutorado em Conservação e Manejo de Vida Silvestre) - Universidade Federal de Minas Gerais, 2012.

Viveiros de Castro, E. B. Encontros: a arte da entrevista. Rio de Janeiro: Azougue, 2007.

Viveiros de Castro, E.B. O anti-Narciso: lugar e função da antropologia no mundo contemporâneo. Revista Brasileira de Psicanálise, 44(4), 15-26, 2010. Disponível em: <http://pepsic. bvsalud.org/pdf/rbp/v44n4/a02.pdf>. 